\title{
A Systematic Review of the Literature on Aspects Affecting Positive Classroom Climate in Multicultural Early Childhood Education
}

\author{
Andrea Khalfaoui $^{1}$ (D) Rocío García-Carrión ${ }^{2}$ D $\cdot$ Lourdes Villardón-Gallego $^{3}$ (D)
}

Published online: 16 March 2020

(c) The Author(s) 2020

\begin{abstract}
The risk for many young children from minority backgrounds of being excluded from a quality education might be reduced through the creation of a positive classroom climate. A systematic review was conducted to gain a better understanding of the pedagogical and structural aspects that foster a positive classroom climate in multicultural early childhood education settings. Following a systematic review procedure, 14 articles were selected and included in the analysis. The findings indicate that eight aspects contribute to a positive climate in these settings: on the one hand, pedagogical practices, including increased instructional time, teacher-student supportive interactions, peer interactions and friendship, child engagement, teacher training on emotionally supportive environments and teacher-family trust-based relationships, and on the other hand, structural aspects, including small peer groups and materials shared among children. This evidence may be used to foster a classroom climate that enhances learning processes and social development in multicultural preschool groups. However, more research is needed to better understand the particular role that cultural diversity plays in the classroom climate.
\end{abstract}

Keywords Classroom climate $\cdot$ Cultural diversity $\cdot$ Minority background $\cdot$ Early childhood education $\cdot$ Systematic review

\section{Introduction}

As the United Nations stated in the fourth Sustainable Development Goal, obtaining a quality education is the foundation for creating sustainable development aimed at achieving fairer and more supportive societies. Early childhood education plays a key role in establishing the foundations for human development and lifelong learning opportunities. Consequently, ensuring equitable, quality education for all

Rocío García-Carrión

rocio.garcia@deusto.es

Andrea Khalfaoui

andrea.khalfaoui@deusto.es

Lourdes Villardón-Gallego

lourdes.villardon@deusto.es

1 Faculty of Psychology and Education, University of Deusto, Avenida de Las Universidades, 24., 48007 Bilbao, Spain

2 Faculty of Psychology and Education, Ikerbasque Science Foundation, University of Deusto, Avenida de Las Universidades, 24., 48007 Bilbao, Spain

3 Department of Didactics and Curricular Development, University of Deusto, Avenida de Las Universidades, 24., 48007 Bilbao, Spain children in their early years, especially for those living in most disadvantaged conditions, has become essential in the current society (Aboud and Yousafzai 2016; Black et al. 2017). The quality of early childhood education is usually defined according to two main dimensions that have consistently been identified in the literature as crucial to fostering children's learning and development. On the one hand, the quality of pedagogical practices (such as planning and implementing learning activities and supporting children's emotional development through positive relationships) seem crucial for cognitive and social development. On the other hand, structural aspects (such as adult-child ratios, staff qualifications, group sizes and characteristics of the physical space) also play a role in ensuring quality in early childhood education and care (ECEC) (Mathers et al. 2014).

Both dimensions also shape the classroom climate based on how social interactions between children and between children and the teacher occur through pedagogical practices in the classroom. Indeed, from an ecological lens, the classroom is understood as a primary micro-context in which students and the teacher interact and where the quality of interactions between the child and elements of the child's proximal environments influence developmental outcomes (Melhuish et al. 2013). Specifically, the classroom climate 
refers to the global classroom atmosphere that is shaped by the interactions that take place in the classroom as a whole, including the teacher's behaviour, students' responses to the teacher, the teacher's response to students, and interactions among students (Gazelle 2006). The classroom climate is reported to be a "positive climate" when a sense of connectedness and belongingness, enjoyment and enthusiasm, and respect are observed among the students and in the teacher-student relationship. Conversely, a "negative climate" is reported when a sense of frequent disruption, conflict, and disorganization is observed (Gazelle 2006; Reyes et al. 2012).

According to the "Teaching Through Interactions" framework (Hamre et al. 2013), a teacher being warm and supportive and providing behavioural and instructional support contributes to a positive classroom climate. In this context, children show not only better language development (Cameron et al. 2008; Pianta et al. 2008) but also better mathematical skills (Curby et al. 2009; Horan and Carr 2018) and behavioural development (Luckner and Pianta 2011; Mashburn et al. 2008). Previous research has shown that students who report having better quality relationships with their teachers also report being approximately three times more engaged in academic tasks and tend to choose more complex cognitive activities (Klem and Connell 2004). Similarly, Hamre and Pianta (2007) found that students who have a greater emotional bond with their teacher are more engaged in learning. In classrooms with a positive climate, teachers spend a minimal amount of time on basic management activities and transitions, and they actively engage children in instructional activities through interesting activities and materials.

Thus, the classroom climate may favour or hinder academic performance and social relationships in the classroom (Howes et al. 2011) since it has the potential to enhance learning and development among preschoolers while fostering social cohesion among school communities (BrophyHerb et al. 2007). However, some communities are less likely to have positive classroom climates. In particular, many students who belong to ethnic minorities are more likely to be placed in classrooms where quality interactions do not usually occur. As a result, these children are often at greater risk of underachieving and not fulfilling their potential (Langeloo et al. 2019). Hence, given the benefits of a positive classroom climate for children's learning and development, the fact that ethnic minority students often receive less benefit from school settings than non-minority students raises important questions related to how educators and educational researchers can ensure a positive classroom climate for children from minority backgrounds.

Since societies are becoming more diverse as a result of migration and displacement, school settings are also becoming more culturally and linguistically diverse worldwide and are serving a high number of students who belong to cultural and ethnic minorities, such as immigrants, refugees, and Roma children. Schools serving these students are mostly located in high-poverty areas in which educational inequalities for historically marginalized students still prevail in many countries (Lampert et al. 2019). Consequently, many children from minority backgrounds experience fewer opportunities to engage in rich interactions that contribute to their development of cognitive and social competences (Mathers et al. 2014; Ball 2012; Heller et al. 2012). Moreover, most of them are often less exposed to the school culture or the language of instruction at home prior to entering early education (Souto-Manning and Mitchell 2010). Hence, many of those children tend to score below their less-disadvantaged peers and to have higher rates of conflicts (Weinstein et al. 2004).

Given this reality, it is particularly important that optimal conditions for a positive classroom climate are created in classrooms serving young children from minority backgrounds due to the relevance of such conditions for fostering educational and social success (Justice et al. 2018; Rios-Gonzalez et al. 2019). Recent research in the field has pointed out the importance of encouraging an ongoing dialogue between families and teachers, to agree on the messages and responses to provide children, in order to build a positive classroom climate free of violence (Rios-Gonzalez et al. 2019). To obtain deeper insight into how to promote a positive classroom climate that advances quality education for all students from their early years, this systematic review aimed to develop a better understanding of the pedagogical and structural aspects that foster a positive classroom climate in preschools that serve children from minority backgrounds. In the following sections, the methods used in this systematic review, including the search procedure, inclusion and exclusion criteria and data analysis, will be presented, followed by the results obtained and finally a discussion of the results and some conclusions.

\section{Method}

This systematic review was based on the detailed procedure described by Moher et al. (2009) for synthesizing evidence in a specific field in an exhaustive and accurate manner. The search, selection and extraction pathways were conducted according to the Preferred Reporting Items for Systematic Reviews and Meta-Analyses (PRISMA) statement to guarantee the transparency, validity, replicability, and updateability of the study (Moher et al. 2009). The PRISMA statement provides a series of clearly defined stages that ensure the accuracy of the research process and the utility of the results. The formulation of the research question was based on the Population, Intervention or Indicator, and Context of 
the study (PICo) approach (Boland et al. 2017). Following this approach, this systematic review aims to respond to the following question: Which pedagogical or structural aspects are related to a positive classroom climate in early childhood education in culturally diverse contexts?

The search plan and analysis stage, specifically the identification of an answerable question and the development of the inclusion and exclusion criteria, were based on Gough and Thomas's (2016) contributions to the field of systematic reviews in educational research. The data synthesis procedure was based on the work of Lockwood et al. (2015) with the goal of gathering, rather than interpreting, the findings of the studies included.

\section{Search Procedure}

An extensive search was initially conducted using the Web of Science (WoS) database with 40 combinations of the following words and phrases: preschool, early childhood, kindergarten, early years, classroom climate, peer relations, school harmony, school climate, classroom environment, cultural diversity, multicul* ${ }^{*}$. These keywords were compared against the United Nations Educational, Scientific and Cultural Organization (UNESCO) thesaurus to ensure their reliability (Gough and Thomas 2016). Before executing the searches, we applied three filters in the search engine: (a) the area filter, which was specified as "education and educational research" to ensure the suitability of the studies found; (b) the date filter, which was set to limit the search to publications from 2008 to 2018 to ensure the timeliness of the studies; and (c) the type of document, as only articles published in scientific journals, and no book chapters, reports or proceedings of conferences, were considered.

\section{Study Selection: Inclusion and Exclusion Criteria}

The aim was to explore aspects that contribute to a positive classroom climate in culturally diverse early childhood education. Accordingly, studies were first selected if they were published between 2008 and 2018 and were focused on early childhood and if at least $15 \%$ of the included students had minority backgrounds. Second, articles needed to provide evidence of aspects related to a positive classroom climate (e.g., children's social skills, prosocial behaviour, teacher-child interactions, and conflict resolution). Third, studies were excluded if they were conducted outside of naturalistic school settings (such as the laboratory, the playground, or home). More specifically, the studies needed to include research carried out in the regular classroom. In summary, articles were not considered for final analysis if the research (a) was not focused on a positive classroom climate, (b) was conducted in a monocultural school setting, or (c) was focused on any educational stage subsequent to early childhood education.

A total of 298 articles were found and recorded in an analysis chart that was shared among three researchers. In this table, key information was recorded for all articles (references in the APA 6th edition format, the combination of keywords through which each article was identified, and the abstracts), and a column was added for each inclusion and exclusion criterion. The exclusion criteria were also recorded in detail for each case. This procedure is summarized in the following flowchart (Fig. 1).

\section{Analysis}

Fourteen articles were scrutinized and analysed in depth. For each of the studies, general information about the study (country, participants, and methods) was obtained and included in Table 1 (see Table 1). Brief information regarding participants' ethnic backgrounds was included to provide an overview of the cultural diversity present in the studies. The analysis focused on the identification of aspects related to a positive classroom climate in the studies selected; therefore, the main aspects identified in each study were included in the table. To provide a clear picture of the studies analysed, the articles were organized in the table according to the focus of the research. Consequently, we grouped the articles into three main topics: first, eight studies focused on teacher education/behaviours; second, four articles focused on peer interactions; and finally, two articles focused on child engagement.

\section{Results}

The analysis of the 14 articles selected for this review sheds light on aspects related to a positive classroom climate that can be categorized as "static" aspects, such as grouping, materials or decorative elements, or "dynamic" aspects, such as time or the quality of instruction, teacher-children interactions, and relationships with family members. These aspects can be grouped under the two dimensions that have been agreed upon in the literature to define quality in early childhood education: "structural aspects" and "pedagogical practices" (Andrews et al. 2014; Barros et al. 2016; Løkken et al. 2018; Mathers et al. 2014). In Fig. 2, we classify the aspects that emerged in the studies as fostering a positive classroom climate for preschoolers with minority backgrounds according to these two dimensions.

\section{Pedagogical Practices}

Twelve of the fourteen articles analysed reported pedagogical practices related to a positive classroom climate. 
Fig. 1 Flow diagram

Potential studies identified from Web of Science published between 2008-2018 $(n=298)$
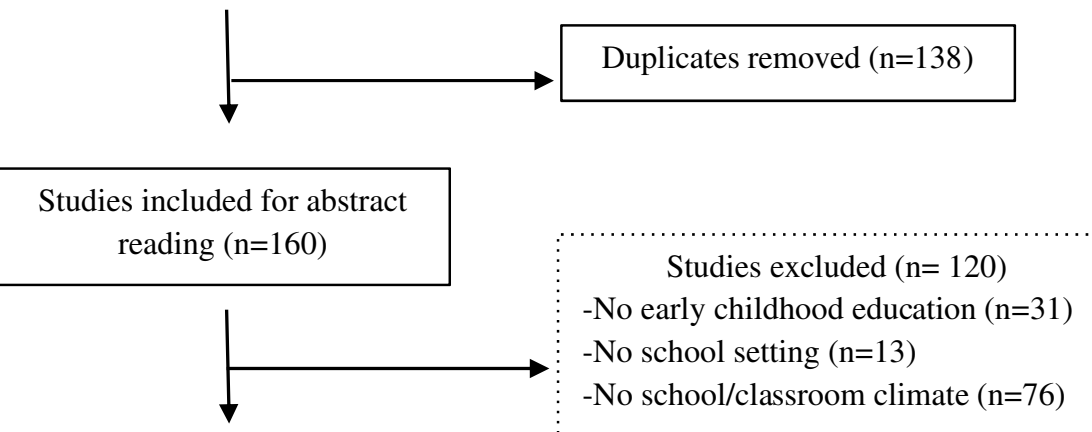

Studies to potentially be included in the review after full document screening $(n=40)$

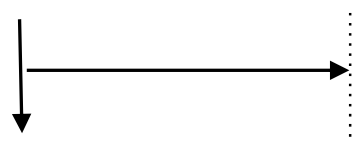

Studies excluded $(n=26)$ -No early childhood education $(n=15)$ -No cultural diversity $(n=11)$

Total studies included for review $(n=14)$

Specifically, these articles focused on (a) instructional interactions between teachers and students, (b) student engagement in classroom tasks, (c) teacher training on emotionally supportive environments and (d) teacher-family relationships. These practices are presented in detail as follows.

First, the articles highlighted the role that instruction plays in favouring a positive climate in the classroom: increased instructional time and an emphasis on academic competences that foster cognitive development (such as literacy skills) help improve the classroom climate. In particular, the benefits reported in two of the studies highlighted a decrease in classroom disruption and conflicts (Howes et al. 2013; Hartman and Manfra 2016). Likewise, the more instructionally and emotionally supportive teacherstudent relationships are, the more the positive classroom climate (Morris et al. 2013). Howes et al. (2013) noted that an instructional climate characterized by aspects such as productivity, concept development, quality of feedback and children's engagement contributes to an improved classroom climate in ECEC (Howes et al. 2013). However, excessive control or an excessively tight schedule in instruction hinders the positive classroom climate in culturally diverse ECEC (Hartman and Manfra 2016).
Certain forms of interaction between teachers and students favour a positive classroom climate (Howes et al. 2011, 2013; Myers and Sheddield 2009). When the teacher supports and encourages academic tasks, offers feedback tailored to each situation and each child, asks questions, asks for further information, repeats student contributions and encourages participation from a place of respect and support without using sarcasm, there are fewer conflicts in the classroom, and disruptive behaviours decrease (Morris et al. 2013; Stanton-Chapman 2014; Spivak and Farran 2016). Likewise, being close to all students should be a priority for teaching staff in classrooms (Stanton-Chapman 2014; Curby et al. 2013). This objective can be achieved by, for example, teachers knowing the name of each child in the classroom or addressing the student with a moderate tone of voice. The care aspect is also an important component of this equation: when children feel cared for and included in the classroom (by having clear rules that provide security and knowing that their needs and demands are met) by the lead teacher, relations between teachers and students improve, which is reflected in the classroom climate (Myers and Sheddield 2009; Johnson et al. 2013). Maintaining high expectations with all students also positively impacts classroom climate 


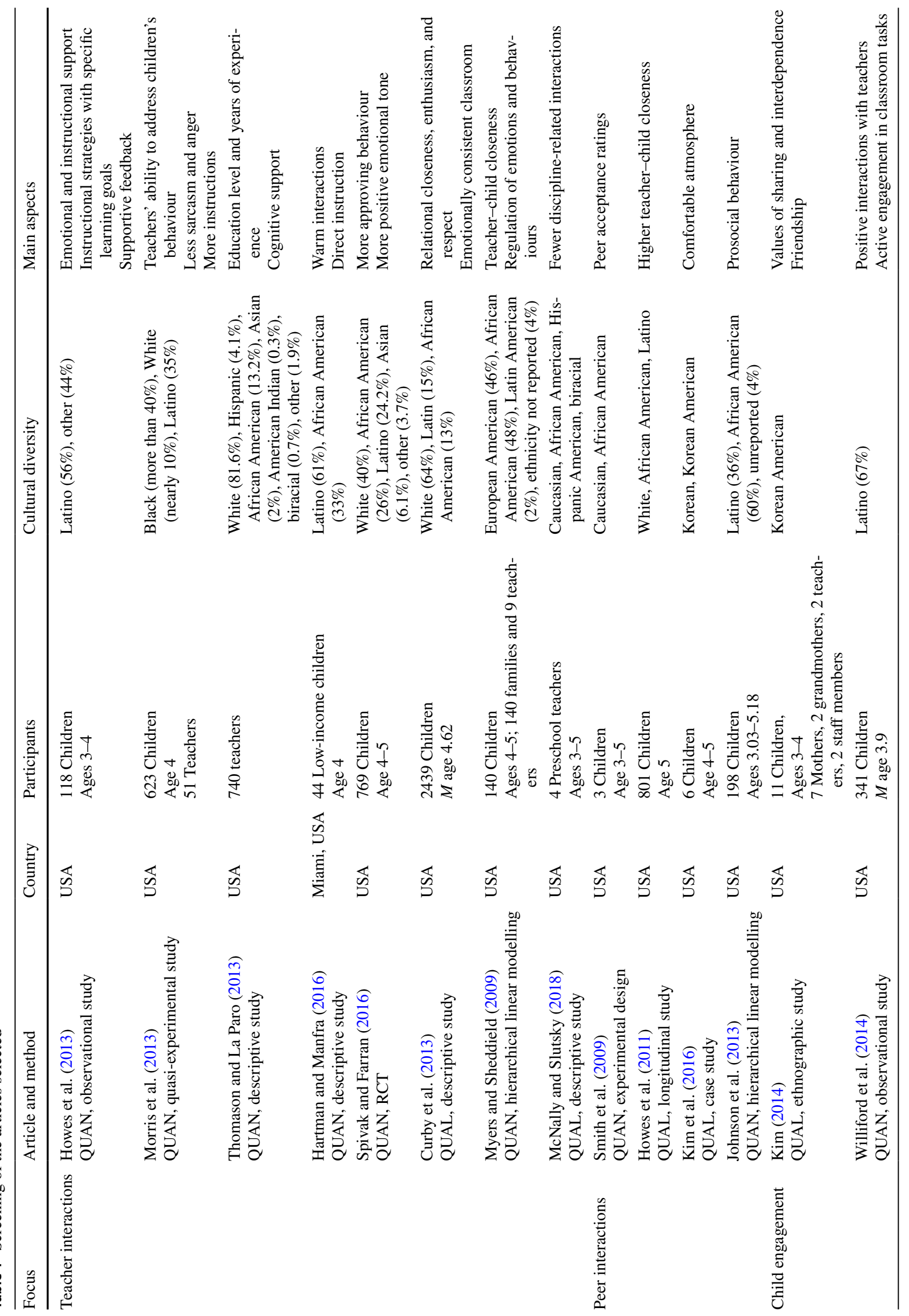


Fig. 2 Categorization of the main aspects fostering a positive classroom climate
Pedagogical Practices

Structural Aspects

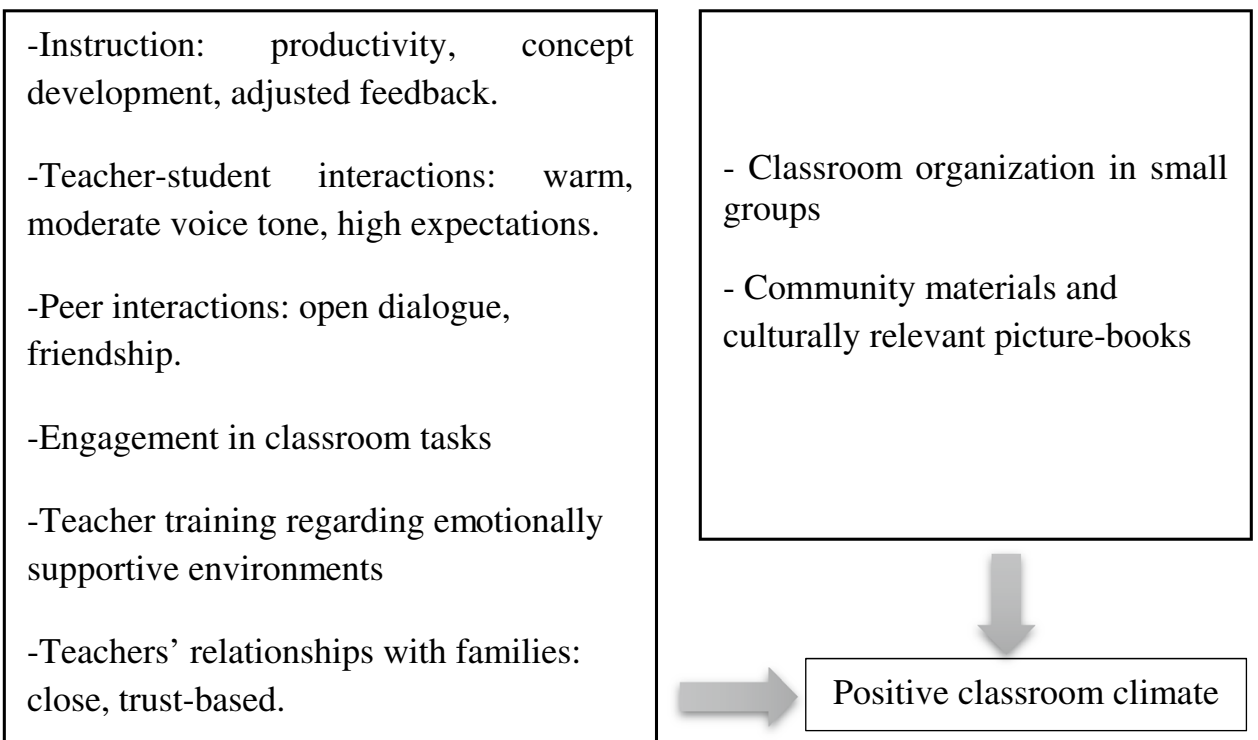

in culturally diverse early childhood education settings (Howes et al. 2011).

During instructional time, certain conditions, such as open dialogue and respect for speaking time, facilitate stronger friendship relationships among students (Kim 2014; Williford et al. 2014). Friendships in the classroom contribute to an enhanced positive classroom climate by reducing conflicts, increasing student participation, and fostering safe and respectful environments (Kim 2014, 2016; Myers and Sheddield 2009; Hartman and Manfra 2016; Smith et al. 2009).

Second, children's engagement in classroom tasks and activities can promote a positive classroom climate since children's active engagement in tasks is associated with gains in emotion regulation. This becomes particularly relevant since successful emotion regulation influences children's functioning in behavioural, academic, and social domains to foster a positive atmosphere in the classroom (Williford et al. 2014).

Third, teacher training has a positive effect on the classroom climate (Howes et al. 2013; Morris et al. 2013; McNally and Slutsky 2018). Two articles indicated that the school should facilitate continuous ECEC training for teachers. In an experimental study, Morris et al. (2013) showed that teachers who had been trained to promote prosocial behaviours and limit disruptive behaviours had fewer conflicts in their classrooms and made better use of the learning time. Likewise, McNally and Slutsky (2018) reported that teachers' professional development related to interactions that contribute to emotionally supportive environments translated into fewer discipline-related behaviours and more emotionally supportive, trust-based behaviours in their classrooms.

Finally, when the relationship between teachers and families is close and based on trust, a positive classroom climate is reported. Engaging in close and trust-based relationships entails, for instance, teachers knowing the names of their students and students' families or legal guardians, and establishing a cordial relationship with them during school entry and exit (McNally and Slutsky 2018). In the same vein, teachers with close relationships with students and their families tend to build an atmosphere of respect with students as well as their families in which children feel respected and safe, as well as motivated and excited to engage in learning opportunities. In the US, this tendency was reported to be particularly important in classrooms where more than half of the children were Latino and did not speak English as their mother tongue (Howes et al. 2013).

\section{Structural Aspects}

In this category, we include the results related to (a) the group size and (b) the physical space of the classroom. This section includes information contained in four of the fourteen articles analysed.

These four articles indicated that organizing a classroom into small groups and offering school material in a way that invites peer-to-peer sharing (e.g., no names on pencils) favours a positive classroom climate in culturally diverse 
school settings (Kim 2014; Howes et al. 2011; McNally and Slutsky 2018).

In ECEC, organizing the class group into small groups allows for more dialogue among the children in each group, which, with clear rules that foster a safe classroom framework, reduces conflict (Howes et al. 2011; Williford et al. 2014). Collective moments (dialogues open to the whole class) also contribute to a lower number of conflicts when children work in small groups (Kim 2014). Johnson et al. (2013) found that in classrooms with a positive climate in which students were organized into small groups, children who were living with a caregiver with depressive symptomatology showed improvements in their prosocial behaviour (Johnson et al. 2013).

In culturally diverse contexts, the selection of children's literature that references the diverse cultural backgrounds of the students present in the classroom fosters a sense of community in the classroom, which helps to improve the classroom climate (Kim 2016). In particular, culturally relevant picture books are shared by young children in the classroom, and children engage in interactions around the books, creating a supportive literature environment in which children also share their experiences from their diverse social backgrounds. Structural aspects, such as providing community materials in the classroom or ensuring moments to work in small groups, contribute to improving the classroom climate in culturally diverse early childhood settings.

\section{Discussion and Conclusions}

With the aim of identifying pedagogical and structural aspects that foster a positive classroom climate in preschool contexts, this systematic review analysed fourteen studies conducted in early years classrooms serving children from minority backgrounds. Overall, the studies addressed some of the main aspects that underlie the classroom climate, such as teacher interactions, peer interactions and child engagement. This finding is consistent with the definition of classroom climate included above and indicates how the classroom atmosphere is shaped by the interactions that take place in the classroom as a whole, including the teacher's behaviour, students' responses to the teacher, the teacher's response to students, and interactions among students (Gazelle 2006). Whereas the previous literature differentiates between positive and negative classroom climate, we decided to explore the aspects related to a positive classroom climate. Specifically, we examined the aspects that lead to a sense of connectedness and an emotionally supportive atmosphere with decreased conflicts and disruptions (Gazelle 2006; Reyes et al. 2012). Overall, eight main aspects related to pedagogical practices and structural aspects emerged from our analysis, which can be discussed with reference to the existing literature in the field.

Classrooms that emphasize instruction through emotional support create an atmosphere where children's behavioural problems and conflicts decrease (Howes et al. 2013; Hartman and Manfra 2016). Particularly, according to Harman and Manfra (2016), children's behavioural problems decrease when they receive warm, direct instruction related to prosocial skills. This is especially important for children with minority backgrounds since a disciplinary environment in the classroom and the school have been reported to have negative effects for more vulnerable students (Mallett 2017). Similarly, the concept of "authentic instruction" emphasizes the importance of the social and emotional aspects of learning that teachers should guarantee (Reyes et al. 2012), such as by offering adjusted feedback and ensuring conceptual development and productivity (Howes et al. 2013). This is consistent with a recent study conducted in the US with 267 children and 93 early educators that showed that children in classrooms characterized by higher levels of emotional support experienced greater improvement in their overall relationships and closeness with the teacher and their peers (Moen et al. 2019).

The relationships that children have with the teacher and their peers shape the atmosphere of the classroom. Therefore, engaging in quality interactions is fundamental to constructing a positive classroom climate, which has also been reported to lead to benefits in cognitive development. Warm, respectful, and emotionally supportive interactions can improve students' learning processes. Accordingly, we identified the following important aspects of child-teacher interactions: for teachers, knowing the name of each child in the classroom, addressing students with a moderate tone of voice and ensuring the establishment of clear rules that provide security, and for children, knowing that their needs and demands are met (Myers and Sheddield 2009; Johnson et al. 2013). These aspects of quality child-teacher interactions shape teachers' positive and encouraging expectations in classrooms serving children with minority backgrounds (Howes et al. 2011). Consequently, professional development that provides teachers with the tools to establish those interactions contributes to fostering a safe and supportive environment (McNally and Slutsky 2018).

Similarly, peer interactions are a key element for boosting children's friendships and positive relationships to foster safe and respectful classroom environments. Indeed, children's friendships contribute to reducing conflicts, increasing student participation, and fostering safe and respectful classroom environments (Fink and Hugues 2019; Kim 2014, Myers and Sheddield 2009; Hartman and Manfra 2016). This is consistent with a study conducted by Oh and Lee (2019) on Korean immigrant children's perspectives of friendship in the USA; the authors found that children 
recognized friendship based on qualitative interactions that included respect and the offering of mutual help. The results of this systematic review align with the findings of Oh and Lee (2019) on the importance of creating multiple opportunities for interaction and collaboration with diverse peers to encourage mutual appreciation and learning since mutual appreciation and learning are particularly important for the promotion of a positive classroom climate (Reyes et al. 2012).

The organization of the classroom in small groups is a structural aspect that favours children's interactions and engagement in instructional tasks (Howes et al. 2011). This finding is consistent with previous research that explored classrooms serving mostly Roma preschool students and reported that a particular small group organization, referred to as 'interactive groups', promoted an inclusive and emotionally supportive climate (Aubert et al. 2017). Similarly, the organization of culturally and linguistically diverse classrooms into heterogeneous groups capitalizes on children's and families' funds of knowledge. This strategy has been shown to be a facilitator of inclusion and social cohesion (Valls and Kyriakides 2013; Reid et al. 2015), as it increases the presence of the child's home culture and family values in the classroom (Souto-Manning and Mitchell 2010). Along these lines, including books, materials or print environments that reflect cultural diversity stimulates peer dialogues that help children affirm their identities and that show them they are a part of the community in which they live (Bennett et al. 2017; Kim 2016). In the print environment, which includes posters and decorative artifacts, picture books also contribute to the creation of a supportive literature environment in which children share their experiences from their diverse social backgrounds.

Finally, these pedagogical and structural aspects contribute to fostering close, trust-based relationships between teachers and families, which is especially true for among cultural minorities (Souto-Manning and Swick 2006; Howes et al. 2013). In addition, Rios-Gonzalez et al. (2019) emphasized the importance of encouraging ongoing dialogue between families and teachers so they can agree on the messages and responses provided to children to develop a positive classroom climate.

\section{Limitations and Further Research}

Among the limitations most frequently highlighted by the studies analysed, the most prominent limitation was the absence of qualitative techniques that would allow for a deeper understanding of the aspects that contribute to improving the classroom climate in the early years. Of the 14 articles analysed, only two referred to comparing the results obtained with the participants with those of other studies (Kim 2014, 2016). Contributing to improving people's lives is a priority of educational research. Given that research with a social impact has shown the importance of the co-creation of knowledge through the inclusion of the voices of participants though egalitarian dialogue (SolerGallart 2017), it would be interesting to emphasize the importance of including participants' voices in the methodologies used in studies. Longitudinal studies would also be relevant to explore the aspects that affect classroom climate over time. When participants are preschoolers, participation in research is especially challenging; however, the ethical involvement of young children in research is children's right in early childhood research (Tisdall 2015). This is especially relevant when the research topic has to do with children's wellbeing, such as their engagement in a positive classroom climate.

The location of the studies could also be interpreted as a limitation of this systematic review, as most of the studies were conducted in the US and included minority populations, such as African Americans or Latinos. Further empirical research could address this issue by exploring other minorities across more diverse countries to better understand the particular role that cultural diversity plays in fostering a positive classroom climate.

In conclusion, despite the limitations acknowledged, this systemic review has reported the current knowledge of pedagogical and structural aspects to better understand how to foster a positive classroom climate in early childhood education for children with minority backgrounds. Indeed, these results have practical implications. In particular, early years teachers working in culturally diverse classrooms could adjust their own practices to foster cognitively and emotionally supportive interactions with their students and among their students and could structure classrooms in small groups, as well as implement other practices found to be beneficial for a positive classroom climate. Overall, for many young children belonging to cultural minorities, the risk of being excluded from a quality education might be reduced if their teachers create a positive classroom climate.

\section{Conflicts of interest}

The authors declare no conflict of interest.

Author Contributions Conceptualization, LV-G., RG-C and AK Formal analysis, AK, RG-C Funding acquisition, AK Methodology, RG-C, LV-G., AK Writing-original draft, AK and LV-G Writing-review \& editing, RG-C, LV-G. 
Funding This research was funded by Basque Government Predoctoral Programme, Grant Number: PRE_1_234.

Open Access This article is licensed under a Creative Commons Attribution 4.0 International License, which permits use, sharing, adaptation, distribution and reproduction in any medium or format, as long as you give appropriate credit to the original author(s) and the source, provide a link to the Creative Commons licence, and indicate if changes were made. The images or other third party material in this article are included in the article's Creative Commons licence, unless indicated otherwise in a credit line to the material. If material is not included in the article's Creative Commons licence and your intended use is not permitted by statutory regulation or exceeds the permitted use, you will need to obtain permission directly from the copyright holder. To view a copy of this licence, visit http://creativecommons.org/licenses/by/4.0/.

\section{References}

Andrews, N., Hanish, L. D., Fabes, R. A., \& Martin, C. (2014). With whom and where you play: Preschoolers' social context predicts peer victimization. Social Development, 23(2), 357-375. https:// doi.org/10.1038/jid.2014.371.

Aboud, F. E., \& Yousafzai, A. K. (2016). Very early childhood development. In Reproductive, maternal, newborn, and child health: Disease control priorities (3 ed.). (pp. 241-261). https://doi. org/10.1596/978-1-4648-0348-2_ch13

Aubert, A., Molina, S., Schubert, T., \& Vidu, A. (2017). Learning and inclusivity via Interactive Groups in early childhood education and care in the Hope school, Spain. Learning, Culture and Social Interaction, 13, 90-103. https://doi.org/10.1016/j. lcsi.2017.03.002.

Ball, A. F. (2012). To know is not enough: Knowledge, power, and the zone of generativity. Educational Researcher, 41(8), 283-293. https://doi.org/10.3102/0013189X12465334.

Barros, S., Cadima, J., Bryant, D. M., Coelho, V., Pinto, A. I., Pessanha, M., et al. (2016). Infant child care quality in Portugal : Associations with structural characteristics. Early Childhood Research Quarterly, 37, 118-130.

Bennett, S. V., Gunn, A. A., Gayle-Evans, G., Barrera, E. S., \& Leung, C. B. (2017). Culturally responsive literacy practices in an early childhood community. Early Childhood Education Journal, 46(2), 241-248. https://doi.org/10.1007/s10643-017-0839-9.

Black, M. M., Walker, S. P., Fernald, L. C. H., Andersen, C. T., DiGirolamo, A. M., Lu, C., et al. (2017). Early childhood development coming of age: Science through the life course. The Lancet, 389(10064), 77-90. https://doi.org/10.1016/S0140 $-6736(16) 31389-7$.

Boland, A., Cherry, G., \& Dickson, R. (Eds.). (2017). Doing a systematic review: A student's guide. Thousand Oaks: Sage.

Brophy-Herb, H. E., Lee, R. E., Nievar, M. A., \& Stollak, G. (2007). Preschoolers' social competence: Relations to family characteristics, teacher behaviors and classroom climate. Journal of Applied Developmental Psychology, 28(2), 134-148. https://doi. org/10.1016/j.appdev.2006.12.004.

Cameron, C. E., McDonald Connor, C., Morrison, F. J., \& Jewkes, A. M. (2008). Effects of classroom organization on letter-word reading in first grade. Journal of School Psychology, 46, 173-192. https://doi.org/10.1016/J.JSP.2007.03.002.

Curby, T. W., Brock, L. L., \& Hamre, B. K. (2013). Teachers' emotional support consistency predicts children's achievement gains and social skills. Early Education and Development, 24(3), 292309. https://doi.org/10.1080/10409289.2012.665760.
Curby, T. W., LoCasale-Crouch, J., Konold, T. R., Pianta, R. C., Howes, C., Burchinal, M., et al. (2009). The relations of observed pre-K classroom quality profiles to children's achievement and social competence. Early Education and Development, 20(2), 346-372. https://doi.org/10.1080/10409280802581284.

Fink, E., \& Hughes, C. (2019). Children's friendships. Pychologist, 32, 28-31. https://doi.org/10.17863/CAM.40186.

Gazelle, H. (2006). Class climate moderates peer relations and emotional adjustment in children with an early childhood history of anxious solitude: A child $\times$ environment model. Developmental Psychology, 42, 1179-1192. https://doi. org/10.1037/0012-1649.42.6.1179.

Gough, D., \& Thomas, J. (2016). Systematic reviews of research in education: Aims, myths and multiple methods. Review of Education, 4(1), 84-102. https://doi.org/10.1002/rev3.3068.

Hamre, B. K., Pianta, R. C., Downer, J. T., DeCoster, J., Mashburn, A. J., Jones, S. M., et al. (2013). Teaching through interactions. The Elementary School Journal, 113(4), 461-487. https://doi. org/10.1086/669616.

Hamre, B. K., \& Pianta, R. C. (2007). Learning opportunities in preschool and early elementary classrooms. In R. C. Pianta, M. Cox, $\&$ K. L. Snow (Eds.), School readiness and the transition to kindergarten in the era of accountability (pp. 49-83). Baltimore, MD: Paul H. Brookes.

Hartman, S., \& Manfra, L. (2016). Change in child behaviour concerns associated with childcare quality features among a sample of low-income Latino children. Early Child Development and Care, 186(9), 1378-1391. https://doi.org/10.1080/03004 430.2015.1095019.

Heller, S. S., Rice, J., Boothe, A., Sidell, M., Vaughn, K., Keyes, A., et al. (2012). Social-emotional development, school readiness, teacher-child interactions, and classroom environment. Early Education and Development, 23(6), 919-944. https://doi. org/10.1080/10409289.2011.626387.

Horan, E., \& Carr, M. (2018). How much guidance do students need? An intervention study on kindergarten mathematics with manipulatives. International Journal of Educational Psychology, 7(3), 286-316. https://doi.org/10.17583/ijep.2018.3672.

Howes, C., Fuligni, A. S., Hong, S. S., Huang, Y. D., \& Lara-Cinisomo, S. (2013). The Preschool instructional context and child-teacher relationships. Early Education and Development, 24(3), 273-291. https://doi.org/10.1080/10409289.2011.649664.

Howes, C., Wishard Guerra, A., Fuligni, A., Zucker, E., Lee, L., Obregon, N. B., et al. (2011). Classroom dimensions predict early peer interaction when children are diverse in ethnicity, race, and home language. Early Childhood Research Quarterly, 26(4), 399-408. https://doi.org/10.1016/j.ecresq.2011.02.004.

Johnson, S. R., Seidenfeld, A. M., Izard, C. E., \& Kobak, R. (2013). Can classroom emotional support enhance prosocial development among children with depressed caregivers? Early Childhood Research Quarterly, 28(2), 282-290. https://doi.org/10.1016/j. ecresq.2012.07.003.

Justice, L. M., Jiang, H., \& Strasser, K. (2018). Linguistic environment of preschool classrooms: What dimensions support children's language growth? Early Childhood Research Quarterly, 42(2017), 79-92. https://doi.org/10.1016/j.ecresq.2017.09.003.

Kim, J. (2014). "You don't need to be mean. We're friends, Right?": Young Korean-American children' s conflicts and references to friendship. Journal of Early Childhood Research, 12(3), 279-293. https://doi.org/10.1177/1476718X14538591.

Kim, S. J. (2016). The role of peer relationships and interactions in preschool bilingual children's responses to picture books. Journal of Early Childhood Literacy, 16(3), 311-337. https://doi. org/10.1177/1468798415577874.

Kim, S. J., Wee, S. J., \& Lee, Y. M. (2016). Teaching kindergartners racial diversity through multicultural literature: A case study 
in a kindergarten classroom in Korea. Early Education and Development, 27(3), 402-420. https://doi.org/10.1080/10409 289.2015.1069110.

Klem, A. M., \& Connell, J. P. (2004). Relationships matter: Linking teacher support to student engagement and achievement. Journal of School Health, 74, 262-273. https://doi. org/10.1111/j.1746-1561.2004.tb08283.x.

Lampert, J., Ball, A., Garcia-Carrion, R., \& Burnett, B. (2019). Poverty and schooling: Three cases from Australia, the United States, and Spain. Asia-Pacific Journal of Teacher Education, 00(00), 1-19. https://doi.org/10.1080/1359866X.2019.1602863.

Langeloo, A., Mascareño Lara, M., Deunk, M. I., Klitzing, N. F., \& Strijbos, J. W. (2019). A systematic review of teacher-child interactions with multilingual young children. Review of Educational Research, 89(4), 536-568. https://doi.org/10.3102/0034654319 855619.

Lockwood, C., Munn, Z., \& Porritt, K. (2015). Qualitative research synthesis: Methodological guidance for systematic reviewers utilizing meta-aggregation. International Journal of Evidence-Based Healthcare, 13(3), 179-187. https://doi.org/10.1097/XEB.00000 00000000062

Løkken, I. M., Bjørnestad, E., Broekhuizen, M. L., \& Moser, T. (2018). The relationship between structural factors and interaction quality in Norwegian ECEC for toddlers. International Journal of Child Care and Education Policy. https://doi.org/10.1186/s4072 3-018-0048-z.

Luckner, A. E., \& Pianta, R. C. (2011). Teacher-student interactions in fifth grade classrooms: Relations with children's peer behavior. Journal of Applied Developmental Psychology, 32, 257-266. https ://doi.org/10.1016/j.appdev.2011.02.010.

Mallett, C. A. (2017). The school-to-prison pipeline: Disproportionate impact on vulnerable children and adolescents. Education and Urban Society, 49(6), 563-592. https://doi.org/10.1177/00131 24516644053

McNally, S., \& Slutsky, R. (2018). Teacher-child relationships make all the difference: constructing quality interactions in early childhood settings. Early Child Development and Care, 188(5), 508-523. https://doi.org/10.1080/03004430.2017.1417854.

Mashburn, A. J., Pianta, R. C., Hamre, B. K., Downer, J. T., Barbarin, O., Bryant, D., et al. (2008). Measures of classroom quality in prekindergarten and children's development of academic, language, and social skills. Child Development, 79, 732-749. https://doi.org /10.1111/j.1467-8624.2008.01154.x.

Mathers, S., Eisenstadt, N., Sylva, K., Soukakou, E., \& Ereky-stevens, K. (2014). Sound foundations: a review of the research evidence on quality of early childhood education and care for children under three implications for policy and practice. The Sutton Trust and the Education Endowment Foundation, 1, 1-68.

Melhuish, E., Quinn, L., Sylva, K., Sammons, P., Siraj-Blatchford, I., \& Taggart, B. (2013). Preschool affects longer term literacy and numeracy: Results from a general population longitudinal study in Northern Ireland. School Effectiveness and School Improvement, 24(2), 234-250. https://doi.org/10.1080/09243453.2012.749796.

Moen, A. L., Sheridan, S. M., Schumacher, R. E., \& Cheng, K. C. (2019). Early childhood student-teacher relationships: What is the role of classroom climate for children who are disadvantaged? Early Childhood Education Journal, 47(3), 331-341. https://doi. org/10.1007/s10643-019-00931-x.

Moher, D., Liberati, A., Tetzlaff, J., Altman, D. G., \& The PRISMA Group. (2009). Preferred reporting items for systematic reviews and meta-analyses: The PRISMA statement. PLoS Med. https:// doi.org/10.1371/journal.pmed.1000097.

Morris, P., Millenky, M., Raver, C. C., \& Jones, S. M. (2013). Does a preschool social and emotional learning intervention pay off for classroom instruction and children's behavior and academic skills? Evidence from the foundations of learning project. Early
Education and Development, 24(7), 1020-1042. https://doi. org/10.1080/10409289.2013.825187.

Myers, S. S., \& Sheddield, A. (2009). Examining associations between effortful control and teacher-child relationships in relation to head start children's socioemotional adjustment. Early Education and Development, 20(5), 756-774. https://doi.org/10.1007/s1046 1-012-0143-z.Provider-patient.

Oh, J., \& Lee, K. (2019). Who is a friend? Voices of young immigrant children. European Early Childhood Education Research Journal, 27(5), 647-661. https://doi.org/10.1080/1350293X.2019.16519 67.

Pianta, R. C., Belsky, J., Vandergrift, N., Houts, R., \& Morrison, F. J. (2008). Classroom effects on children's achievement trajectories in elementary school. American Educational Research Journal, 45, 365-397. https://doi.org/10.3102/0002831207308230.

Reid, J. L., Kagan, S. L., Hilton, M., \& Potter, H. (2015). Diversity in preschool classrooms : The link between diversity and quality in early childhood. Poverty \& Race, 24(3), 199-206.

Reyes, C., Brackett, M. A., Rivers, S. E., White, M., \& Salovey, P. (2012). Classroom emotional climate, student engagement, and academic achievement. Journal of Educational Psychology, 104(3), 700-712. https://doi.org/10.1037/a0027268.

Rios-Gonzalez, O., Puigvert Mallart, L., Sanvicén Torné, P., \& Aubert Simón, A. (2019). Promoting zero violence from early childhood: A case study on the prevention of aggressive behavior in Cappont Nursery. European Early Childhood Education Research Journal, 27(2), 157-169. https://doi.org/10.1080/1350293X.2019.15795 44.

Smith, S. M., Joan, S., \& Bramlett, R. K. (2009). Effects of positive peer reporting (PPR) on social acceptance and negative behaviors among peer-rejected preschool children. Journal of Applied School Psychology, 25(4), 323-341. https://doi.org/10.1080/15377 900802595359.

Soler-Gallart, M. (2017). Achieving social impact. sociology in the public sphere. Basel: Springer.

Souto-Manning, M., \& Mitchell, C. H. (2010). The role of action research in fostering culturally-responsive practices in a preschool classroom. Early Childhood Education Journal, 37(4), 269-277. https://doi.org/10.1007/s10643-009-0345-9.

Souto-Manning, M., \& Swick, K. J. (2006). Teachers' beliefs about parent and family involvement: Rethinking our family involvement paradigm. Early Childhood Education Journal, 34(2), 187-193. https://doi.org/10.1007/s10643-006-0063-5.

Spivak, A. L., \& Farran, D. C. (2016). Predicting first graders' social competence from their preschool classroom interpersonal context. Early Education and Development, 27(6), 735-750. https://doi. org/10.1080/10409289.2016.1138825.

Stanton-Chapman, T. L. (2014). Promoting positive peer interactions in the preschool classroom: The role and the responsibility of the teacher in supporting children's sociodramatic play. Early Childhood Education Journal, 43(2), 99-107. https://doi.org/10.1007/ s10643-014-0635-8.

Thomason, A. C., \& La Paro, K. (2013). Teachers' commitment to the field and teacher-child interactions in center-based child care for toddlers and three-year-olds. Early Childhood Education Journal, 41(3), 227-234. https://doi.org/10.1007/s10643-012-0539-4.

Tisdall, E. K. M. (2015). Participation, Rights and 'Participatory' methods. In A. Farrell, S. L. Kagan, \& E. K. M. Tisdall (Eds.), The SAGE handbook of early childhood research. London: Sage.

Valls, R., \& Kyriakides, L. (2013). The power of Interactive Groups: How diversity of adults volunteering in classroom groups can promote inclusion and success for children of vulnerable minority ethnic populations. Cambridge Journal of Education, 43(1), 17-33. https://doi.org/10.1080/0305764X.2012.749213.

Weinstein, C. S., Tomlinson-Clarke, S., \& Curran, M. (2004). Toward a conception of culturally responsive classroom management. 
Journal of Teacher Education, 55(1), 25-38. https://doi. org/10.1177/0022487103259812.

Williford, A. P., Whittaker, J. E. V., Vitiello, V. E., \& Downer, J. T.

(2014). Children's engagement within the preschool classroom and their development of self-regulation. Early Education and Development, 24(2), 162-187. https://doi.org/10.1080/10409 289.2011.628270.Children.
Publisher's Note Springer Nature remains neutral with regard to jurisdictional claims in published maps and institutional affiliations. 